\title{
Comparison of Sexual Function in Primiparous Women Pre-Pregnancy and Postpartum: Difference of the Sexual Function after the Normal Vaginal Delivery and the Cesarean Section
}

\author{
Fatemeh Nasiri Amiri ${ }^{1}$, Shabnam 0midvar ${ }^{1}$, Afsaneh Bakhtiari ${ }^{1}$, \\ Shala Yazdani' ${ }^{2}$ Mahmood Hajiahmadi ${ }^{3}$ \\ ${ }^{1}$ Departments of Midwifery and Reproductive Health, Faculty of Medicine, Babol University of Medical \\ Sciences, Babol, Iran \\ ${ }^{2}$ Fatemeh Zahra Infertility and Reproductive Health Research Center, Departments of Obstetrics and \\ Gynecology, Babol University of Medical Sciences, Babol, Iran \\ ${ }^{3}$ Departments of Biostatics and Epidemiology, Babol University of Medical Sciences, Babol, Iran \\ Email: nasiriffa@yahoo.com, shomidvar@yahoo.com@yahoo.com, afbakhtiari@gmail.com, \\ shala yazdani 1348@yahoo.com, mahmoodhajiahamadi@yahoo.com,
}

Received 12 August 2015; accepted 26 October 2015; published 29 October 2015

Copyright (C) 2015 by authors and Scientific Research Publishing Inc.

This work is licensed under the Creative Commons Attribution International License (CC BY). http://creativecommons.org/licenses/by/4.0/

(c) (i) Open Access

\section{Abstract}

Introduction: Sexual function is undoubtedly an important dimension of adult life. Due to all the conflicting results with regard to sexual function after the normal vaginal delivery (NVD) or the Cesarean Section (CS), in the present study, we aimed to compare the sexual function in women pre-pregnancy and postpartum and also after the NVD and CS. Materials and Methods: In this cohort study, two groups of healthy women, with antenatal normal pregnancies, who underwent NVD $(n=90)$ and CS $(n=113)$, were prospectively studied. The sexual function of the participants was assessed through a Female Sexual Function Index (FSFI) questionnaire in two stages: once before pregnancy and then within 3 to 6 months after delivery, which lasted from June 2011 to September 2012. The data were analyzed by descriptive and inferential statistics. Data were analyzed using chi-square test, Mann-Whitney test, and T Test. Results: Based on the data gathered from 206 women who completed the FSFI questionnaire in two stages, the mean $( \pm$ SD) self-reported timing of the resumption of sexual activity was $8.9 \pm 1.3$. There was no significant statistical difference found between the two groups by timing of the resumption of sexual activity in NVD and

\footnotetext{
${ }^{*}$ Corresponding author.
}

How to cite this paper: Amiri, F.N., Omidvar, S., Bakhtiari, A., Yazdani, S. and Hajiahmadi, M. (2015) Comparison of Sexual Function in Primiparous Women Pre-Pregnancy and Postpartum: Difference of the Sexual Function after the Normal Vaginal Delivery and the Cesarean Section. Health, 7, 1379-1386. http://dx.doi.org/10.4236/health.2015.710152 
CS groups. There was also no statistically significant difference found in the overall sexual function scores between the two groups (NVD vs. CS). The average score for female sexual function in desire, arousal, orgasm, and satisfaction within 3 to 6 months after delivery was significantly lower than that of their pre-pregnancy period $(p<0.004)$. The mean coitus in postpartum period was $1.84 \pm 1.20$ per week. Conclusion: Based on the findings of this study, there was no significant relationship between the mode of delivery and changes in sexual function. Therefore, it can be claimed that CS is not preferred to NVD with regard to preserving normal sexual functioning.

\section{Keywords}

Women's Health, Cesarean Section, Postpartum, Vaginal Delivery, Female Sexual Function

\section{Introduction}

Sexual performance and satisfaction are the most important aspects of women's lives [1]. Sexual dysfunction in women is defined as the inability to achieve orgasm [2]. The American Foundation for Urologic Disease has confirmed four types of female sexual dysfunction: low libido, problems with sexual arousal, inability to achieve orgasm, and dyspareunia [3]. Recent studies have found that the prevalence of female sexual dysfunction (approximately 40\%) outstrips that of males (approximately 30\%) [4] [5]. Despite the fact that there is a high prevalence in female sexual dysfunction, there have been few research studies investigating female sexual problems [6].

The accurate prevalence of female sexual dysfunction is unknown in our community, but the prevalence of sexual dysfunctions in American men and women, according to the report released by National Health and Social Life Survey, are 31\% and 43\% respectively [7]. Lack of libido, inability to reach orgasm and sexual pleasure, and pain during sexual intercourse are among the most common sexual problems women usually suffer from [8]. It has also been shown that the frequency of sexual activity during pregnancy [9] and postpartum [10] can be reduced, but the results are by no means consistent. Several studies have also shown that sexual problems are more common among women with pelvic floor muscle disorders [11]-[13]. It is worth mentioning that a lot of biological and psychosocial changes can occur during pregnancy and the post partum period, but unfortunately not all women adapt well to these changes [14]-[16].

There is a positive association between the severity of dyspareunia and perinealtrauma (in particular, episiotomy) [17]-[19]. The interesting fact is that some women prefer Caesarean Section (CS) to vaginal delivery as they believe that they will have a smaller chance of dyspareunia in their postpartum period. But obviously, there is still doubt that the mode of delivery is associated with female sexual function [17] [18] [20].

Normally, women under do Cesarean section in case a known medical condition is threatening the life of mother or the baby [21]. But nowadays the tendency of women, with no medical indications, to CS is on the rise, which has made CS a popular mode of delivery around the globe [22]. That CS should be performed under maternal request or the physicians' recommendation is still a controversial issue [23]. The World Health Organization (WHO) has reported that the rate of CS is $10 \%-15 \%$ in the world [24]. It is worth noting that the rate of CS in Iran has experienced a six-fold increase in the last three decades [25]. These findings are congruous with the previous results, shedding light on the fact that the rate of CS in Iran is increasingly on the rise [26] [27]. But, there has been a long-standing controversy over what is the best mode of delivery (VD vs. CS) to diminish the risk of postnatal morbidity, which has not only affected the professionals' perspectives to the issue, but also changed the way women look at the childbirth experience [28].

Despite all the controversies and the significance of the issue, not enough research has been conducted so far to pinpoint the problem more accurately. To this end, the present study aimed to compare the postpartum sexual function in primiparous women after vaginal delivery and Caesarian Section in Babol.

\section{Materials and Methods}

This cohort study was carried out based on the prospective study of women with antenatal normal pregnancy at the first trimester and followed until after delivery, who had undergone NVD and CS. This study was conducted in health centers affiliated to Babol University of Medical Sciences in Babol, Iran, from June 2011 to September 
2012. The area of health care centers related to Babol University of Medical Sciences in Babol was divided into four zones, namely North, South, West and East, and then one center was selected from each zone randomly. Participants were selected by two stage sampling. A total 240 pregnant women had been referred to the health clinics at Babol University of Medical Sciences were recruited consecutively. Eligible women presented to the above health centers were selected for participation in study, so 228 women met the study criteria, and of whom, 203 (113 with CS and 90 with NVD) completed whole study period. In the first stage of study 228 pregnant women who referred to receipt prenatal care were questioned about their pre-pregnancy Sexual Function. In the second stage of study the women who had brought their babies to same health clinics for immunization 3 to 6 months after delivery $(n=203)$ were questioned about their postpartum Sexual Function 0.25 of the women (10.1\%) did not participate in the second stage sampling for various reasons.

The inclusion criteria for the study were: giving prenatal care in the first trimester and then they had brought their babies to the same health clinics for immunization after delivery within 3 to 6 months through Caesarean Section or vaginal delivery with episiotomy, negative history of instrumental vaginal delivery.

Data collection tool was a questionnaire, completed by the researchers through interviews. Because of the vaginitis on the sexual function, if subjects have symptoms of vaginitis, they were excluded. So the participants with the following criteria were excluded from the study: having a child with anomalies, preterm delivery, previous pelvic surgery, the history of previous marriage, the history of sub-fertility, the body mass index of $>30$, consuming medications with adverse effects on sexual function (e.g., blood pressure lowering drugs, antiarrhythmia drugs, sedatives and tricyclic anti-depressants), having physical and mental problems, the presence of relationship problem with their spouse, mental retardation, smoking and alcohol consumption, and having a critical misfortune such as the death of relatives in the past year.

An informed consent was obtained from each participant through the provision of an information leaflet coupled with verbal reassurance that participation was entirely voluntary and that the participant could withdraw at any time. All participants were assured in terms of confidentiality and anonymity. In addition, all participants were requested to put their responded questionnaires in a covered box.

Data collection tool was a questionnaire completed through interviews in private meetings by the researcher. The questionnaire comprised two parts: Socio demographic characteristics (age, level of education, employment, and the partner's age, job, and level of education) and obstetric history (type of birth, episiotomy, parity, infant's gender, birth weight of infants, contraceptive methods used) and gynecological status (the symptoms of vaginitis, breastfeeding) and other information (the time for the resumption of sexual intercourse and the frequency of sexual contacts per week). The second part of the questionnaire concerned the sexual functioning prior to pregnancy and the period within 3 to 6 months postpartum. The sexual function was measured on the basis of a valid and reliable Female Sexual Function Index (FSFI) questionnaire. Female Sexual Function Index, as a generic standard questionnaire, contains 19 items and addresses women's sexual function in 6 dimensions including sexual desire (frequency and level of sexual desire), arousal (frequency and level of arousal and satisfaction with sexual arousal), lubrication (frequency and difficulty of vaginal lubrication and problems in orgasm related to vaginal lubrication), orgasm (frequency of orgasm, difficulty in reaching orgasm and satisfaction with orgasm), satisfaction (satisfaction with emotional closeness with a spouse, satisfactory sex with the spouse and the overall life satisfaction) and pain (frequency and level of pain during and after intercourse) [6]. The higher score means better sexual functioning. The psychometric properties of this questionnaire were confirmed by some studies [6] [29]. The validity and reliability of this questionnaire on women with sexual dysfunction and control groups have been reported in a study by Mohhamadi et al. (2008) in Iran. The Cronbach's alpha for the sexual function index and its dimensions ranged between 0.70 (sexual desire) to 0.91 (orgasm) [30]. The construct validity of the questionnaire established and reported in a study by Khademi et al. (2006) [31] on 547 Iranian women indicated 5 dimensions, which were comparable with the original factors used in a study by Rosen et al. [6]. The data were analyzed by descriptive and inferential statistics. The analyses of findings were done by the statistical package for social sciences (SPSS V.18) software. $P$ values less than .05 were considered significant.

Differences in variables between groups were determined with the Student's two tailed $t$ test and for dichotomous and normally distributed continuous variables, respectively. Proportions were compared using ChiSquare test. Analysis of variance was used to test for significance of difference between means in groups.

\section{Ethical Considerations}

This study was approved by the Ethics Medical Research Committee of Babol University of Medical Sciences. 
The participants had been given a written informed consent before the study commenced. The use of numbers ensured the confidentiality of the task, and no names appeared anywhere on the questionnaires.

\section{Results}

The present study was conducted on a total number of 203 primiparous women (90 women with episiotomy who had NVD, and 113 women who had CS) within 3 to 6 months after their delivery. The socio-demographic characteristics of the women are shown in Table 1 . The age range of the participants was 18 to 40 year. The mean age of women was $24.91 \pm 4.9$, and the mean age of their husbands was $29.9 \pm 5$. 7. The length of their marriage was $5.93 \pm 5.4$ years on average. All of them were breast-feeding their kids.

According to the data, the scores related to sexual function did not differ significantly among two groups (NVD $(n=90)$ and CS $(n=113)$ with regard to duration of marriage, educational level, contraception methods, and occupational status (Table 1). The birth weight of the neonates was between 2500 to 4000 grams in $82.9 \%$ of cases. There was also no difference between the groups with regard to the birth weight of their neonates (Table 1). The comparison between pre-pregnancy and postpartum female sexual function scores is shown in Table 2. The average score of female sexual function with regard to desire, arousal, orgasm and satisfaction within the period of 3 to 6 months after delivery was significantly lower than that of pre-pregnancy $(p<0.004)$. It is also worth noting that significant decreases in the test scores were observed for all the key dimensions of sexual function (desire, arousal, orgasm, and satisfaction).

Table 1. The socio-demographic characteristics of the women after delivery with NVD and CS.

\begin{tabular}{|c|c|c|c|}
\hline Characteristics & $\begin{array}{c}\text { Women with NVD } \\
\text { Number (\%) }\end{array}$ & $\begin{array}{l}\text { Women with CS } \\
\text { Number (\%) }\end{array}$ & $\mathrm{P}$ value \\
\hline $\begin{array}{l}\text { Educational level: } \\
\text { High school or higher } \\
\text { Primary School }\end{array}$ & $\begin{array}{l}66(75.0) \\
24(25.0)\end{array}$ & $\begin{array}{l}84(73.4) \\
29(26.6)\end{array}$ & N.S* \\
\hline $\begin{array}{c}\text { Occupational Status: } \\
\text { Employees } \\
\text { Housewife }\end{array}$ & $\begin{array}{l}66(75.9) \\
21(24.1)\end{array}$ & $\begin{array}{l}86(76.1) \\
27(23.9)\end{array}$ & N.S \\
\hline $\begin{array}{l}\text { Sex baby: } \\
\text { Boy } \\
\text { Girl }\end{array}$ & $\begin{array}{l}46(51.1) \\
44(49.9)\end{array}$ & $\begin{array}{l}60(53.1) \\
53(46.9)\end{array}$ & N.S \\
\hline $\begin{array}{c}\text { Birth Weight: } \\
<2500 \\
2500-4000 \\
>4000\end{array}$ & $\begin{array}{c}5(5.6) \\
75(83.3) \\
10(11.1)\end{array}$ & $\begin{array}{c}7(6.2) \\
93(82.3) \\
13(11.5)\end{array}$ & NS \\
\hline $\begin{array}{c}\text { Contraception Methods after de } \\
\text { Condom } \\
\text { Withdrawal } \\
\text { mini-pill } \\
\text { intrauterine device } \\
\text { other contraceptive }\end{array}$ & $\begin{array}{l}38(43.2) \\
32(36.4) \\
15(17) \\
2(2.3) \\
1(1.1)\end{array}$ & $\begin{array}{c}48(42.5) \\
40(35.5) \\
18(15.9) \\
4(3.5) \\
3(2.6)\end{array}$ & NS \\
\hline
\end{tabular}

"NS = Not significant.

Table 2. The FSFI scores in pre-pregnancy and postpartum women.

\begin{tabular}{cccc}
\hline Domain & Pre-pregnancy & Postpartum & P value \\
\hline Desire & $7.0 \pm 1.7$ & $5.9 \pm 1.7$ & 0.000 \\
Arousal & $6.6 \pm 1.7$ & $5.9 \pm 1.7$ & 0.000 \\
Orgasm & $7.5 \pm 1.6$ & $7.0 \pm 1.7$ & 0.000 \\
Pain & $6.9 \pm 2.0$ & $6.8 \pm 2.0$ & 0.4 \\
Lubrication & $7.5 \pm 1.5$ & $7.5 \pm 1.6$ & 0.48 \\
Satisfaction & $8.2 \pm 1.4$ & $7.9 \pm 1.6$ & 0.004 \\
\hline
\end{tabular}


In the two groups (NVD and CS), the relationship between the maternal age and the sex ualorgasm before pregnancy and after delivery was found to be inversely correlated $(\mathrm{R}=-0.19, P=0.02)$. But there was no significant difference between the ages of their husbands. The mean $( \pm S D)$ self-reported timing of the resumption of sexual activity in two groups (NVD and CS), were $8.9 \pm 1.3$ and $8.6 \pm 1.1$ respectively. There was no significant difference between the two groups $(p=0.66)$. Also, there was no significant correlation between the onset of the resumption of sexual activity and the birth weight of the neonates. The FSFI scores of the two groups and the comparison between them are given in Table 3.

There was also no statistically significant difference between the sexual function scores of two groups (NVD and CS) $(p=0.8)$. In overall the methods of contraception in postpartum cases were: condoms $(42.2 \%)$, withdrawal (35.7\%), mini-pill (16.1\%), the intrauterine device, IUD, (1\%), and other contraceptive methods (3\%). The percentage of women who went without contraception was $2 \%$. It should be noted that there was no correlation found between the method of contraception in post partum and the sexual function scores.

It is also worth mentioning that the increase in dyspareunia was associated with the decrease in orgasm in the pre-pregnancy $(\mathrm{R}=-0.34, p=0.002)$ as well as the post partum periods $(\mathrm{R}=-0.13, p=0.037)$. The mean coitus in postpartum period was $1.84 \pm 1.20$ per week. There was a significant difference between the pre-pregnancy and the postpartum period in two groups $(p<0.05)$.

\section{Discussion}

The results of the current study showed that there was no difference between primiparous women who had vaginal delivery through midiolateral episiotomy and those who experienced Cesarean Section with regard to their sexual function. This finding is in line with Baytur et al.'s study which concluded that the mode of delivery had no impact on the sexual function of women [32]. But this result seems to be incongruous with that of Lydon-Rochelle et al. [33] which concluded that within 7 weeks of postpartum, women who had undergone CS, or had experienced instrument-assisted vaginal labors had significantly lower general health and sexual function scores compared with those who had normal vaginal delivery.

Signorello et al. [34] also proposed that the use of obstetric instruments and the degree of perineal trauma positively correlated with the severity of postpartum dyspareunia, impaired sexual sensation, sexual satisfaction, and the ability to achieve orgasm. But these findings largely depend on the short-term changes in postpartum sexual function.

Furthermore, the decrease in postpartum sexual function in women may also be attributed to a hypo estrogenic state that can occur due to lactation; emotional and relational changes such as the changing body image; fatigue brought about by the baby's needs; and the quality of the relationship with her spouse [32]. The present study, however, proved that there was no difference between the two groups in terms of long-term sexual dysfunction, and that the sexual function of women does not seem to be related to the mode of delivery.

Another study by Lagana et al. demonstrated that female sexual dysfunction in patients who underwent episiotomy during delivery markedly led to low FSFI scores [35]. There is, however, a little consensus among researchers as to whether episiotomy can specifically predispose women to sexual dysfunction. In a longitudinal prospective study, the delivery mode and the episiotomy were reportedly not associated with anorgasmia in primiparous women [36]. Also, according to the systematic review evaluating the outcomes of routine episiotomy, no evidence was found to support the fact that episiotomy reduced impaired sexual function [37]. Hannah et al., in a randomized study of vaginal delivery versus elective CS for singleton fetus in breech presentation, suggested that there was no difference in sexual outcome between 3 months and 2 years postpartum outcomes [38].

Table 3. The FSFI scores in NVD and CS groups within 3 to 6 months after delivery.

\begin{tabular}{cccc}
\hline Domain & NVD $(\mathrm{N}=90)$ & CS $(\mathrm{N}=113)$ & $\mathrm{P}$ value \\
Desire & $5.9 \pm 1.7$ & $6.1 \pm 1.5$ & $\mathrm{P}=0.20$ \\
Arousal & $5.9 \pm 1.6$ & $5.8 \pm 1.7$ & $\mathrm{P}=0.35$ \\
Orgasm & $7.1 \pm 1.4$ & $6.9 \pm 1.8$ & $\mathrm{P}=0.19$ \\
Pain & $6.8 \pm 1.5$ & $6.7 \pm 1.7$ & $\mathrm{P}=0.34$ \\
Lubrication & $7.0 \pm 1.6$ & $7.1 \pm 1.5$ & $\mathrm{P}=0.33$ \\
Satisfaction & $6.8 \pm 1.2$ & $6.9 \pm 1.2$ & $\mathrm{P}=0.50 \quad$ \\
\hline
\end{tabular}


The sexual function is significantly decreased within 3 to 6 months after the childbirth compared with the prepregnancy period. These differences between pre-pregnancy and postpartum scores seemed to be mostly due to desire, arousal, orgasm, and the satisfaction domain of the test.

This finding is consistent with those of Brown and Lumley [39], Walraven et al. [40], and Barrett et al. [41], which suggested that the sexual function in women, within 3 to 6 months after delivery, was significantly lower than that of pre-pregnancy period. Breast-feeding seems to be closely associated with the poor postpartum sexual functioning in women [42]. Since the participants of the present study were still breast-feeding their babies, such concerns are not applicable to the population of this study. The average onset of sexual intercourse, according to previous studies, is 5 to 8weeksafter the delivery [43] [44], but the results of this study showed that the mean time for the resumption of sexual intercourse was $8.95 \pm 1.3$ weeks, which is in line with the result of a study by Anzaku and Mikah [45]. What makes the present study distinct from the previous studies is the use of a validated sexual function instrument in a prospective, multicenter study with carefully characterized obstetric patients. Like any other studies, this study is not without limitations. Sexual function is very complicated and is affected by many factors, including the person's lifestyle, interpersonal relationships and cultural conditions. Although it was basically designed to address the impact of the mode of delivery on the sexual functioning of women, it failed to show a relationship between the method of delivery and all of the postpartum sexual problems, which could be due to the limited sample size and sampling method (self-reported questionnaire) Thus, the results of the present study cannot be generalized within the population of the present study or across other cultures.

\section{Conclusion}

In conclusion, based on the findings of this study, there was no significant relationship between the mode of delivery and changes in sexual function. Therefore, it can be claimed that CS is not preferred to NVD with regard to preserving normal sexual functioning.

\section{Acknowledgements}

We are deeply indebted to each of the participants for their substantial time, effort, and contribution to this study. We would also like to appreciate Babol University of Medical Sciences for its approval and funding.

\section{Authors' Contribution}

Fatemeh Nasiri Amiri and Shabnam Omidvar contributed to study design, execution, analysis, manuscript drafting, and critical discussion. Afsaneh Bakhtiari and Shala Yazdani contributed in study design, manuscript drafting, and language editing. Mahmood Hajiahmadi contributed in study design, manuscript drafting, analysis, and critical discussion. All authors read and approved the final manuscript.

\section{Financial Disclosure}

There was no financial disclosure.

\section{References}

[1] Litzinger, S. and Gordon, K.C. (2005) Exploring Relationships among Communication, Sexual Satisfaction, and Marital Satisfaction. Journal of Sex \& Marital Therapy, 31, 409-424. http://dx.doi.org/10.1080/00926230591006719

[2] Buhling, K.J., Schmidt, S., Robinson, J.N., Klapp, C., Siebert, G. and Dudenhausen, J.W. (2006) Rate of Dyspareunia after Delivery in Primiparae According to Mode of Delivery. European Journal of Obstetrics \& Gynecology and Reproductive, 124, 42-46. http://dx.doi.org/10.1016/j.ejogrb.2005.04.008

[3] Basson, R., Leiblum, S., Brotto, L., et al. (2004) Revised Definitions of Women's Sexual Dysfunction. The Journal of Sexual Medicine, 1, 40-48. http://dx.doi.org/10.1111/j.1743-6109.2004.10107.x

[4] Laumann, E.O., Paik, A. and Rosen, R.C. (1999) Sexual Dysfunction in the United States: Prevalence and Predictors. Journal of the American Medical Association, 281, 537-544. http://dx.doi.org/10.1001/jama.281.6.537

[5] Read, S., King, M. and Watson, J. (1997) Sexual Dysfunction in Primary Medical Care: Prevalence, Characteristics and Detection by the General Practitioner. Journal of Public Health, 19, 387-391.

http://dx.doi.org/10.1093/oxfordjournals.pubmed.a024665 
[6] Rosen, R., Brown, C., Heiman, J., Leiblum, S., Meston, R., Shabsigh, R., et al. (2000) The Female Sexual Function Index (FSFI): A Multidimensional Self-Report Instrument for the Assessment of Female Sexual Function. Journal of Sex \& Marital Therapy, 26, 191-208. http://dx.doi.org/10.1080/009262300278597

[7] Nappi, R., Salonia, A., Traish, A.M., van Lunsen, R.H., Vardi, Y., et al. (2005) Clinical Biologic Pathophysiologies of Women's Sexual Dysfunction. The Journal of Sexual Medicine, 2, 4-25. http://dx.doi.org/10.1111/j.1743-6109.2005.20102.x

[8] Laumann, E.O., Paik, A. and Rosen, R.C. (1999) Sexual Dysfunction in the United States: Prevalence and Predictors. Journal of the American Medical Association, 28, 537-544. http://dx.doi.org/10.1001/jama.281.6.537

[9] Bartellas, E., Crane, J.M., Daley, M., Bennett, K.A. and Hutchens, D. (2000) Sexuality and Sexual Activity in Pregnancy. BJOG: An International Journal of Obstetrics \& Gynaecology, 107, 964-968. http://dx.doi.org/10.1111/j.1471-0528.2000.tb10397.x

[10] DeJudicibus, M.A. and McCabe, M.P. (2002) Psychological Factors and the Sexuality of Pregnant and Postpartum Women. Journal of Sex Research, 39, 94-103. http://dx.doi.org/10.1080/00224490209552128

[11] Handa, V.L., Harvey, L., Cundiff, G.W., Siddique, S.A. and Kjerulff, K.H. (2004) Sexual Function among Women with Urinary Incontinence and Pelvic Organ Prolapse. American Journal of Obstetrics and Gynecology, 191, 751-756. http://dx.doi.org/10.1016/j.ajog.2003.11.017

[12] Barber, M.D., Visco, A.G., Wyman, J.F., Fantl, J.A. and Bump, R.C. (2002) Sexual Function in Women with Urinary Incontinence and Pelvic Organ Prolapse. Obstetrics \& Gynecology, 99, 281-289. http://dx.doi.org/10.1016/S0029-7844(01)01727-6

[13] Lukacz, E.S., Whitcomb, E.L., Lawrence, J.M., Nager, C.W., Contreras, R. and Luber, K.M. (2007) Are Sexual Activity and Satisfaction Affected by Pelvic Floor Disorders? Analysis of a Community-Based Survey. American Journal of Obstetrics and Gynecology, 197, 88.e1-88.e6. http://dx.doi.org/10.1016/j.ajog.2007.02.053

[14] Abdool, Z., Thakar, R. and Sultan, A.H. (2009) Postpartum Female Sexual Function. European Journal of Obstetrics \& Gynecology and Reproductive Biology, 145, 133-137. http://dx.doi.org/10.1016/j.ejogrb.2009.04.014

[15] Gjerdingen, D.K. and Center, B.A. (2003) First-Time Parents' Prenatal to Postpartum Changes in Health, and the Relation of Postpartum Health to Work and Partner Characteristics. Journal of the American Board of Family Medicine, 16, 304-311. http://dx.doi.org/10.3122/jabfm.16.4.304

[16] Johnson, C.E. (2011) Sexual Health during Pregnancy and the Postpartum. The Journal of Sexual Medicine, 8, 12671284. http://dx.doi.org/10.1111/j.1743-6109.2011.02223.x

[17] Carroli, G., Belizan, J. and Stamp, G. (1997) Episiotomy Policies in Vaginal Births. In: Neilson, J.P., Crowther, C.A., Hodnett, E.D. and Hofmeyr, G.J., Eds., Pregnancy and Childbirth Module of the Cochrane Database of Systematic Reviews, Available in The Cochrane Library [Database on Disk and CDROM]. The Cochrane Collaboration, Issue 1, Update Software, Oxford, 1998. Updated Quarterly.

[18] Barret, G., Pendry, E. and Peacock, J. (2000) Women’s Sexual Health after Childbirth. BJOG: An International Journal of Obstetrics \& Gynaecology, 107, 186-195. http://dx.doi.org/10.1111/j.1471-0528.2000.tb11689.x

[19] Kettle, C. and Johanson, R.B. (1998) Continuous versus Interrupted Sutures for Perineal Repair. Cochrane Database of Systematic Reviews, No. 1, Article No.: CD000947. http://dx.doi.org/10.1002/14651858.cd000947

[20] Barrett, G., Peacock, J., Victor, C.R. and Manyonda, I. (2005) Cesarean Section and Postnatal Sexual Health. Birth, 32, 306-311. http://dx.doi.org/10.1111/j.0730-7659.2005.00388.x

[21] Ronsmans, C., Holtz, S. and Stanton, C. (2006) Socioeconomic Differentials in Caesarean Rates in Developing Countries: A Retrospective Analysis. The Lancet, 368, 1516-1523. http://dx.doi.org/10.1016/S0140-6736(06)69639-6

[22] Stjernholm, Y.V., Petersson, K. and Eneroth, E. (2010) Changed Indications for Cesarean Sections. Acta Obstetricia et Gynecologica Scandinavica, 89, 49-53. http://dx.doi.org/10.3109/00016340903418777

[23] Chong, Y.S. and Kwek, K.Y. (2010) Safer Childbirth: Avoiding Medical Interventions for Non-Medical Reasons. The Lancet, 375, 440-442. http://dx.doi.org/10.1016/S0140-6736(10)60055-4

[24] World Health Organization (1985) Appropriate Technology for Birth. The Lancet, 2, 436-437.

[25] Badakhsh, M.H., Seifoddin, M., Khodakarami, N., Gholami, R. and Moghimi, S. (2012) Rise in Cesarean Section Rate Over a 30-Year Period in a Public Hospital in Tehran, Iran. Archives of Iranian Medicine, 15, 4-7.

[26] Ahmad-Nia, S., Delavar, B., Eini-Zinab, H., Kazemipour, S., Mehryar, A.H. and Naghavi, M. (2009) Caesarean Section in the Islamic Republic of Iran: Prevalence and Some Sociodemographic Correlates. Eastern Mediterranean Health Journal, 15, 1389-1398.

[27] Moini, A., Riazi, K., Ebrahimi, A. and Ostovan, N. (2007) Caesarean Section Rates in Teaching Hospitals of Tehran: 1999-2003. Eastern Mediterranean Health Journal, 13, 457-460.

[28] Lees, C.C. (2004) Making Sense of Rising Caesarean Section Rates: Editorial Made No Sense of Rising Rates. British 
Medical Journal, 329, 1240. http://dx.doi.org/10.1136/bmj.329.7476.1240

[29] Wiegel, M., Meston, C. and Rosen, R. (2005) The Female Sexual Function Index (FSFI): Cross-Validation and Development of Clinical Cutoff Scores. Journal of Sex \& Marital Therapy, 31, 1-20. http://dx.doi.org/10.1080/00926230590475206

[30] Mohammadi, K.H., Heydari, M. and Faghihzadeh, S. (2008) The Female Sexual Function Index (FSFI): Validation of the Iranian Version. Payesh Journal, 7, 269-278. (In Persian)

[31] Khademi, A., Alleyassin, A., Agha-Hosseini, M., Dadras, N., Asghari Roodsari, A., Tabatabaeefar, L., et al. (2006) Psychometric Properties of Sexual Function Questionnaire: Evaluation of an Iranian Sample. Iranian Journal of Reproductive Medicine, 4, 23-28. (In Persian)

[32] Baytur, Y.B., Deveci, A., Uyar, Y., Ozcakir, H.T., Kizilkaya, S. and Caglar, H. (2005) Mode of Delivery and Pelvic Floor Muscle Strength and Sexual Function after Childbirth. International Journal of Gynecology \& Obstetrics, 88, 276-280. http://dx.doi.org/10.1016/j.ijgo.2004.12.019

[33] Lydon-Rochelle, M.T., Holt, V.L. and Martin, D.P. (2001) Delivery Method and Self-Reported Postpartum General Health Status among Primiparous Women. Paediatric and Perinatal Epidemiology, 15, 232-240. http://dx.doi.org/10.1046/j.1365-3016.2001.00345.x

[34] Signorello, L.B., Harlow, B.L., Chekos, A.K. and Repke, J. (2001) Postpartum Sexual Functioning and Its Relationship to Perineal Trauma: A Retrospective Cohort Study of Primiparous Women. American Journal of Obstetrics and Gynecology, 184, 881-890. http://dx.doi.org/10.1067/mob.2001.113855

[35] Laganà, A.S., Burgio, M.A., Ciancimino, L., Sicilia, A., Pizzo, A., Magno, C., Butticè, S. and Triolo, O. (2014) Evaluation of Recovery and Quality of Sexual Activity in Women during Postpartum in Relation to the Different Mode of Delivery: A Retrospective Analysis. Minerva Ginecologica, 67, 315-320.

[36] Connolly, A., Thorp, J. and Pahel, L. (2005) Effects of Pregnancy and Childbirth on Postpartum Sexual Function: A Longitudinal Prospective Study. International Urogynecology Journal, 16, 263-267. http://dx.doi.org/10.1007/s00192-005-1293-6

[37] Hartmann, K., Viswanathan, M., Palmieri, R., Gartlehner, G., Thorp Jr., J. and Lohr, K.N. (2005) Outcomes of Routine Episiotomy: A Systematic Review. Journal of the American Medical Association, 293, 2141-2148. http://dx.doi.org/10.1001/jama.293.17.2141

[38] Hannah, M.E., Whyte, H., Hannah, W.J., Hewson, S., Amankwah, K., et al. (2004) Maternal Outcomes at 2 Years after Planned Cesarean Section versus Planned Vaginal Birth for Breech Presentation at Term: The International Randomized Term Breech Trial. American Journal of Obstetrics and Gynecology, 191, 917-927. http://dx.doi.org/10.1016/j.ajog.2004.08.004

[39] Brown, S. and Lumley, J. (1998) Maternal Health after Childbirth: Results of an Australian Population Based Survey. BJOG: An International Journal of Obstetrics \& Gynaecology, 105, 156-161. http://dx.doi.org/10.1111/j.1471-0528.1998.tb10045.x

[40] Walraven, G., Scherf, C., West, B., Ekpo, G., Paine, K., Coleman, R., et al. (2001) The Burden of Reproductive Diseases in Rural Women in The Gambia, West Africa. The Lancet, 357, 1161-1167. http://dx.doi.org/10.1016/S0140-6736(00)04333-6

[41] Barret, G., Pendry, E. and Peacock, J. (2001) Victor Cr. Sexual Function after Childbirth: Women Experiences, Persistent Morbidity and Lack of Professional Recognition. BJOG: An International Journal of Obstetrics \& Gynaecology, 105, 242-243. http://dx.doi.org/10.1111/j.1471-0528.1998.tb10066.x

[42] Yee, L.M., Kaimal, A.J., Nakagawa, S., Houston, K. and Kuppermann, M. (2013) Predictors of Postpartum Sexual Activity and Function in a Diverse Population of Women. Journal of Midwifery \& Women's Health, 58, 654-661. http://dx.doi.org/10.1111/jmwh.12068

[43] Bernnard, L.A. (2002) Sexuality and Sexual Health Care for Women. Clinical Obstetrics \& Gynecology, 45, 10891098. http://dx.doi.org/10.1097/00003081-200212000-00017

[44] Lurie, S., Aizenberg, M., Sulema, V., Boaz, M., Kovo, M., Golan, A. and Sadan, O. (2013) Sexual Function after Childbirth by the Mode of Delivery: A Prospective Study. Archives of Gynecology and Obstetrics, 288, 785-792. http://dx.doi.org/10.1007/s00404-013-2846-4

[45] Anzaku, A.S. and Mikah, S. (2014) Postpartum Resumption of Sexual Activity, Sexual Morbidity and Use of Modern Contraceptives among Nigerian Women in Jos. Annals of Medical and Health Sciences Research, 4, 210-216. http://dx.doi.org/10.4103/2141-9248.129044 